\title{
A review of Tsudayusurika Sasa, 1985 (Diptera: Chironomidae, Orthocladiinae), with the description of a new species
}

\author{
Masaru Yamamoto' and Nao Yamamoto ${ }^{2}$
}

\begin{abstract}
Yamamoto M and Yamamoto N. 2012. A review of Tsudayusurika Sasa, 1985 (Diptera: Chironomidae, Orthocladiinae), with the description of a new species. Fauna norvegica 31: 215-225.

Tsudayusurika Sasa, 1985 is reviewed based on material from Taiwan and Japan. This orthocladiine genus is characterized by having a female antenna with 10 flagellomeres and large and rhombic cerci. The male antenna has 13 flagellomeres and the anal point is transparent, short and prominently wide. Tsudayusurika fudosecunda Sasa, the type species of the genus, and T. multiannulata (Tokunaga) are redescribed. A new species, T. suginoi, from Okinawa Island is described and figured as male and female. Kuroyonyusurika Sasa, 1996 is presented as a new junior synonym of Tsudayusurika and the type species $K$. kuroheius is transferred to this genus and redescribed. Tsudayusurika cladochaita Wang and T. yufunivea (Sasa et Suzuki) are removed from Tsudayusurika and tentatively placed in Bryophaenocladius.
\end{abstract}

doi: 10.5324/fn.v31i0.1401. Received: 2011-10-29. Accepted: 2012-07-05.

Published on paper and online: 2012-10-17.

Keywords: Chironomidae, Orthocladiinae, Tsudayusurika, Japan and Taiwan, new species

1. 1-6-12, Satomachi, Yoshimi, Shimonoseki, Yamaguchi Prefecture, 759-6525, Japan

2. Osaka Prefecture University, Entomological Laboratory, Graduate School of Life and Environment

Science, Nakaku Gakuen-cho 1-1, Sakai, Osaka Prefecture, 599-8531, Japan

Corresponding author: Masaru Yamamoto

E-mail: oceua-m22485@ipone.ne.jp

\section{INTRODUCTION}

Tokunaga (1940) described a curious orthoclad species, Spaniotoma (Orthocladius) multiannulata from Arisan, Formosa (Taiwan), which was characterized by the female having an antenna with 10 flagellomeres and large, rhombic cercus. Although the body coloration and male antennal ratio were given, details of the male and female genitalia were not described. Sasa (1985) erected the genus Tsudayusurika for a new species, T. fudosecunda, from Japan, which has a female antenna with 10 flagellomeres in common with $S$. multiannulata, and he illustrated the male genitalia. Further, Sasa (1996) erected the genus Kuroyonyusurika for a new species, K. kuroheius, from Honshu, Japan. Sæther et al. (2000) transferred this species to Bryophaenocladius Thienemann, 1934 and Yamamoto (2004) accepted this placement. Recently by the courtesy of Mr. H. Sugino of Okinawa Prefecture we had the opportunity to examine specimens identified as Tsudayusurika collected in Yanbaru Forest, Okinawa Island and it became clear that Kuroyonyusurika is a junior synonym of Tsudayusurika.

Identification and delineation of species based on male adults is quite difficult using hypopygial characters, but the females are easily distinguished from each other by the combination of characters in the genitalia, antenna and clypeus. Consequently, we concluded that the specimens collected on Okinawa Island belong to an undescribed species. This species is described and figured below. We also redescribe Tsudayusurika fudosecunda Sasa, 1985, T. kuroheius (Sasa, 1996) and T. multiannulata (Tokunaga, 1940).

\section{MATERIAL AND METHODS}

As the most important taxonomic character appears on the dorsal side of the female genitalia, a few slide-mounted specimens of T. fudosecunda, the type species of Tsudayusurika, 
were remounted. Specimens of the new species and the type specimens of Spaniotoma multiannulata had been preserved in alcohol. After being macerated in $5 \% \mathrm{KOH}$ solution, these specimens were mounted temporarily in glycerol for drawing. The specimens used for description and illustration finally were mounted permanently on slides in Euparal. For the allotype of Spaniotoma multiannulata, the number of temporal setae, clypeal setae, dorsocentral setae, prealar setae and scutellar setae were counted before the specimens were macerated.

The terminology and measurements mainly follow Sæther (1980). Paramere and basal lobe are used as neutral term for phallapodeme and inferior volsella in the male hypopygial structure and egg-guide is used as a neutral term for the lobes of gonapophysis VIII of Sæther (1980) in the female genitalia. The measurements are given as ranges, generally followed by mean when 4 or more measurements were made, followed by the number of specimens measured (n) in parentheses.

The holotype of the new species is housed in the collection of the Osaka Prefecture University, Osaka, Japan.

\section{RESULTS AND DISCUSSION}

\section{Tsudayusurika Sasa}

Tsudayusurika Sasa, 1985: 62. Kuroyonyusurika Sasa, 1996: 23. Syn. nov.

Type species: Tsudayusurika fudosecunda Sasa, 1985, by original designation and monotypy.

Other included species: Tsudayusurika kuroheius (Sasa) comb nov.; T. multiannulata (Tokunaga); T. suginoi sp. nov.

The male diagnosis given by Sasa (1985) is emended and the female is diagnosed in detail.

\section{Diagnosis (emended)}

Head. With well-developed coronal suture in both sexes. Temporal setae uniserial. Clypeus with 2-9 setae in male, 1-10 in female. Stipes nearly triangular in shape. Cornua of cibarial pump distinct. Tentorium slender, long, with or without distinct rounded projection anteriorly. Male antenna with 13 flagellomeres and well developed plume, groove beginning at flagellomere 4; female antenna with 10 flagellomeres, ultimate flagellomere with or without subapical seta. Antennal ratio of male excluding T. kuroheius 1.30-2.44. Flagellomeres 1-9 in female antenna and flagellomeres 1-5 or 6 in male antenna each with a pair of simple long sensilla basiconica; ultimate flagellomere with several simple sensilla basiconica and a few sensilla coeloconica in both sexes.

Thorax. Antepronotum well developed, lobes meeting at distinct V-shaped notch anterior to anterior margin of scutum. Scutum smoothly rounded. Lateral antepronotals 1-4; dorsocentrals erect, several, uniserial; acrostichals weak, starting some distance from antepronotum; prealars several, uniserial; no supraalar. Scutellum with several uniserially setae.
Wing. Membrane bare, covered with microtrichia; anal lobe distinct, rounded. Squama with or without setae. $R$ and $R_{1}$ with several to 10 or more setae; $\mathrm{R}_{4+5}$ with few to 10 or more setae apically in male, with about $10-20$ setae in apical 1/2-3/4 in female.

Legs. Tarsomere 1 and 2 of mid and hind legs with pseudospurs. Sensilla chaetica absent. Claws gradually curved, dentate apically in male, simple in female. Pulvilli absent.

Hypopygium. Anal point very short and prominently wide, hyaline. T IX with paired, low tubercles posteriorlaterally each with about 10 short setae. Paramere large, nearly triangular in shape. Basal lobe of gonocoxite well developed, strongly sclerotized, semicircular or triangular in shape, bare in apical half. Gonostylus gently curved, without crista dorsalis. Megaseta long and slender.

Female genitalia. Tergum IX completely divided into two parts by rather wide or narrow median longitudinal membranous area; each part rather small and completely fused with larger laterosternite (gonocoxite IX sensu Sæther, 1977, 1980). Segment $\mathrm{X}$ without setae. Sternum VIII long, with posteromedian lobe (gonapophysis VIII sensu Sæther, 1977, 1980) with distinct concavity on lateral margin and horizontal concavity anterior to median cleft. Egg-guide divided into large ventrolateral lobe and small dorsomedian lobe. Apodeme lobe small, indistinct. Gonocoxapodeme distinctly curved. Notum as long as or longer than length of sternum VIII. Postgenital plate triangular. Cercus large, long, rhombical and directed posteriorly. Spermathecal duct long, slightly curved. Seminal capsule large, about 1/2-2/3 as long as length of VIII sternum.

Systematic remarks. The genus Tsudayusurika keys to Bryophaenocladius Thienemann in the Holarctic key (Cranston et al. 1989), and in the Manual of Palaearctic Diptera (Sæther et al. 2000). Although Tsudayusurika is characterized by the presence of pseudospurs on tarsomeres, a wide, short, transparent anal point and large, sclerotized basal lobe of gonocoxite in the male, the characters are not sufficient to define Tsudayusurika as a separate genus distinct from Bryophaenocladius. For example, Tsudayusurika shares a wide and short anal point with Bryophaenocladius dentatus, and some species of Bryophaenocladius have comparatively large, sclerotized, bare basal lobes of the gonocoxites in the male. In contrast, although Tsudayusurika shares the eggguide divided into large, rounded ventrolateral lobe and small, narrow dorsomesal lobe with Bryophaenocladius, the females of the genus are distinct based on the following combination of characters: 1) flagellum with 10 flagellomeres ; 2) each flagellomere with simple long sensilla basiconica. As a note here, Cranston (1987) redescribed the parthenogenetic species Bryophaenocladius furcatus (Kieffer, 1916) with unusual forked long sensilla basiconica on each flagellomere. This character also is observable in the Japanese species of the Bryophaenocladius such as B. oirasextus (Sasa, 1991) and B. tusimocedeus (Sasa et Suzuki, 1999); 3) tergum IX completely divided into two parts by a median longitudinal membrane; 
4) laterosternite (gonocoxite IX sensu Sæther, 1977, 1980) completely fused with tergum IX; 5) lateral margins of posteromedian lobes of sternum VIII (gonapophysis VIII sensu Sæther, 1977, 1980) distinctly concave, and posteromedian area of sternum VIII anterior to median cleft with a horizontal concavity; 6) cercus large, long and rhombical, projecting posteriorly. Characters 1, 3, 5 and probably 6 may be suggested as autapomorphous characters for Tsudayusurika. Character 5 may be related to mating behavior; when mating, the anal point and the basal lobes may be fitted in the horizontal and lateral concavities of the posteromedian lobes, respectively. However, to clarify the systematic position of Tsudayusurika, further studies of the immature stages are required.

\section{Keys to species of the genus Isudayusurika \\ Adult males}

Tsudayusurika kuroheius is not included due to insufficient knowledge of diagnostic characters.

1 Ultimate antennal flagellomere with or withut subapical seta; clypeus with 2-4 setae ... 2

- Ultimate antennal flagellomere with subapical seta; clypeus with 7-9 setae T. suginoi

2 Ultimate antennal flagellomere without subapical seta T. fudosecunda

- Ultimate antennal flagellomere with subapical seta T. multiannulata might be placed here, judging from the female characters.

\section{Adult females}

The female of T. kuroheius is not known.

1 Median longitudinal membranous area on T IX very wide (Figure 2A, Figure 8A); ultimate antennal flagellomere with or without subapical seta 2

- Median longitudinal membranous area on T IX narrow (Figure 3B, Figure 5A); ultimate antennal flagellomere with subapical seta (Figure 4C) T. multiannulata

2 Ultimate antennal flagellomere with subapical seta; clypeus with 8-10 setae (Figure 7D) ........ T. suginoi sp. n.

- Ultimate antennal flagellomere without subapical seta; clypeus with 1-4 setae (Figure 1C) ........... T. fudosecunda

\section{Tsudayusurika fudosecunda Sasa}

(Figures 1-2)

Tsudayusurika fudosecunda Sasa, 1985: 62.

Tsudayusurika fudosecunda Sasa; Sæther et al. (2000: 183); Yamamoto (2004: 109).

\section{Material examined.}

Holotype male (NMST Type No. 079:051), Japan, Kyushu, Miyazaki Prefecture, Mts. Kirishima, Lake Fudo, sweep net, 17.xi.1981, M. Sasa; 3 male \& 4 female paratypes (NMST 79: $52-53,63,67-68$ ) as holotype; 8 male paratypes (NMST 79: $54-$ 59, 61-62), as previous except 18.xii.1981.

\section{Diagnostic characters.}

The female of this species shares the median wide longitudinal membranous area with $T$. suginoi sp. n. However the species can be separated from the latter by the ultimate antennal flagellomere lacking subapical seta, fewer setae on clypeus and the semicircular basal lobe of the gonocoxite.

Male ( $\mathrm{n}=12$, unless otherwise stated)

Total length 3.4-4.0, $3.7 \mathrm{~mm}$. Wing 2.3-2.4, $2.4 \mathrm{~mm}$ long, 0.5$0.6,0.6 \mathrm{~mm}$ wide; wing length / wing width $3.77-4.20,4.00$.

Coloration. Head dark brown; mouth parts pale brown. Thorax including antepronotum and pleura predominantly dark brown, scutellum pale brown. Halter pale brown. Squama brown. Legs predominantly brown, all coxae dark brown. Abdomen including genitalia dark brown.

Head. Temporal setae 6-9. AR 1.30-1.60, 1.41. Ultimate flagellomere without subapical seta (Figure 1A). Palpomere lengths (in $\mu \mathrm{m}: \mathrm{n}=9$ ): 22-34, 29; 54-66, 61; 124-164, 145; 108-136, 125; 150-180, 161; with 0, 2-5, 14-22, 9-11, 7-9 setae, respectively; third palpomere with 3-6 sensilla clavata. Cornua well developed. Clypeus with 2-4 setae.

Thorax. Lateral antepronotals 2-4; dorsocentrals 6-8, uniserial; acrostichals 5-9, biserial; prealars 4-6, uniserial; supraalar 0 . Scutellum with 5-8 setae, uniserial.

Wing. Anal lobe rounded. Costal extension as long as RM, ca. $70 \mu \mathrm{m}$ long. VR 1.07-1.22, 1.14 (9). $\mathrm{R}$ with13-19 setae, $\mathrm{R}_{1}$ with 710 , and apical $1 / 2-1 / 7$ of $R_{4+5}$ with $0-7$ setae. Brachiolum with 14, 3 median setae; with 8-11 basal, 3 median and 7-10 subapical sensilla companiformia. Squama with 0-1 seta.

Legs. Fore, mid and hind coxae with 2-3, 5-9, 5-7 marginal setae, respectively; fore, mid and hind trochanters with 5-9, 7-9, 5-9 marginal setae, respectively. Spur of fore tibia 60-70, $66 \mu \mathrm{m}$ long; mid tibia with anteroventral spur 26-32, $29 \mu \mathrm{m}$ and posteroventral spur 42-52, $48 \mu \mathrm{m}$ long; hind tibia with anteroventral spur 30-36, $33 \mu \mathrm{m}$ long and posteroventral spur 66-80, $74 \mu \mathrm{m}$ long. Tibial comb with 7-13 spine-like setae. Lengths and proportions of legs as in Table 1.

Hypopygium (Figure 1B). Tergum IX with 7-11 setae on each side, sternum IX with 11-16 setae dorsolaterally. Gonocoxite 236-276, $254 \mu \mathrm{m}$ long, with large, nearly semicircular basal lobe. Sternapodeme narrow, slightly convex medially, with weak, rounded anterolateral projections. Virga of 4-7 needlelike spines, 20-28, 23 (8) $\mu \mathrm{m}$ long. Gonstylus 112-124, $118 \mu \mathrm{m}$ long; megaseta 20-23, $21 \mu \mathrm{m}$ long. HR 2.03-2.37, 2.15 .

Female ( $\mathrm{n}=4$, unless otherwise stated)

Total length 3.3-3.9, $3.7 \mathrm{~mm}$. Wing 1.5-1.6, $1.6 \mathrm{~mm}$ long; 0.4- 

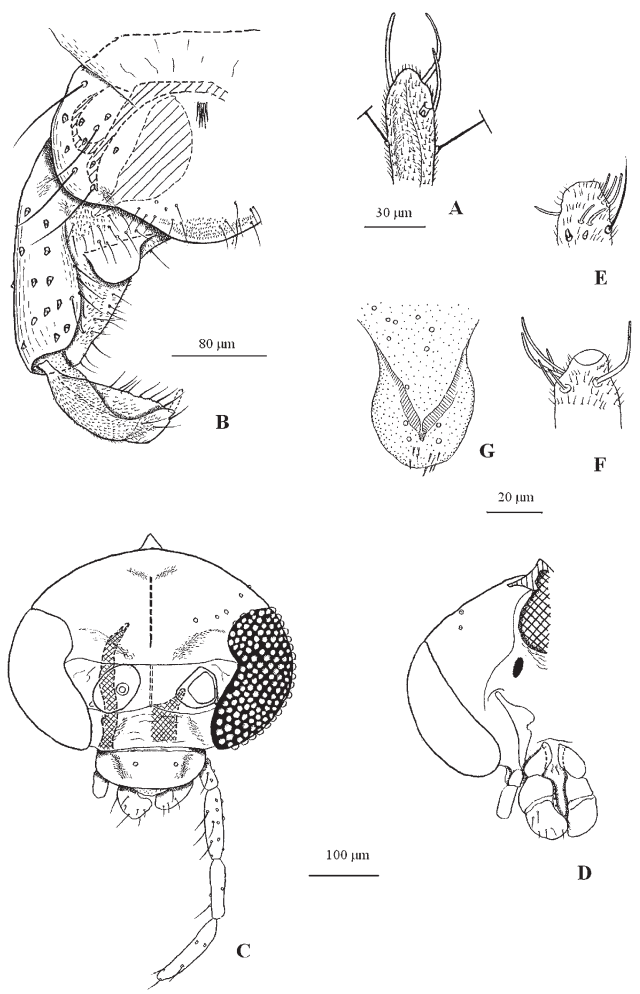

Figure I. Tsudayusurika fudosecunda Sasa, 1985, male (A-B: holotype) and female (C-G: paratypes). A. apex of antenna. B. male hypopygium, dorsal view. C. head, frontal view. D. head, caudal view. E, F. apices of $3^{\text {rd }}$ maxillary palp. G. posterior surface of epipharynx.

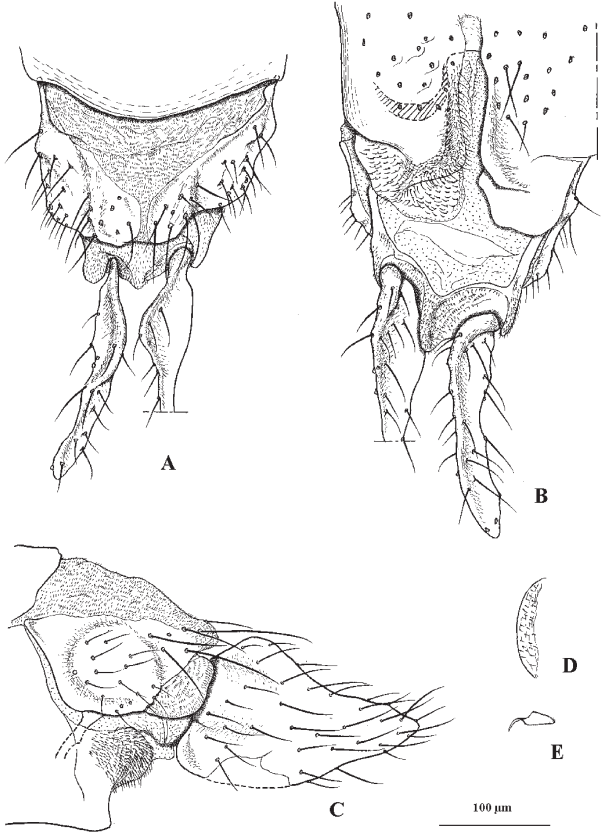

Figure 2. Tsudayusurika fudosecunda Sasa, 1985, female genitalia (paratype). A. dorsal view. B. ventral view. C. lateral view. D. dorsomesal lobe of egg-guide. E. apodeme lobe of egg-guide.
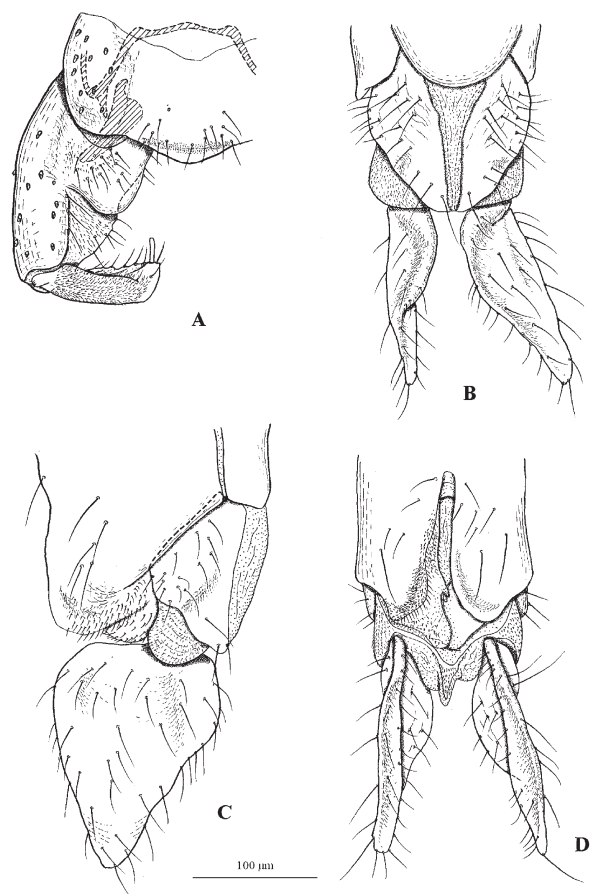

Figure 3. Tsudayusurika spp. A. T. kuroheius (Sasa, 1996), male hypopygium (hototype of Kuroyonyusurika kuroheiua). B-D. T. multiannulata (Tokunaga, 1940), female genitalia (allotype of Spaniotoma multiannulata). A. dorsal view. B. dorsal view. C. lateral view. D. ventral view.

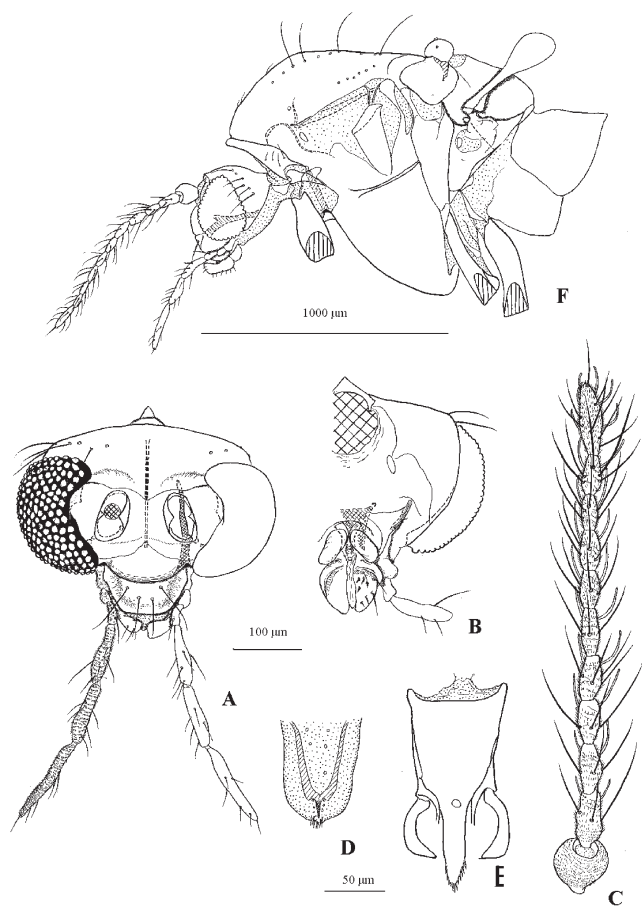

Figure 4. Tsudayusurika multiannulata (Tokunaga, 1940), female (Yakuno, Kyoto Pref., Honshu, Japan). A. head, frontal view. B. head, caudal view. C. antenna. D. posterior surface of epypharynx. E. cibarial pump. F. head and thorax, lateral view. 
Table I. Lengths (in $\mu \mathrm{m}$ ) and proportions of legs of Tsudayusurika fudosecunda Sasa, 1985, male (n =12).

\begin{tabular}{cccccc}
\hline & fe & ti & ta $_{1}$ & ta $_{2}$ & ta $_{3}$ \\
\hline $\mathrm{p}_{1}$ & $1040-1200,1108$ & $1180-1360,1248$ & $860-1020,918(11)$ & $460-560,507(11)$ & $280-340,306(11)$ \\
$\mathrm{p}_{2}$ & $1040-1180,1103$ & $1060-1240,1135$ & $620-800,686$ & $320-380,358$ & $220-260,248$ \\
$\mathrm{p}_{3}$ & $1120-1240,1195$ & $1280-1500,1380$ & $760-900,835(11)$ & $420-480,460(11)$ & $300-340,320(10)$ \\
\hline & \multicolumn{1}{c}{$\mathrm{ta}_{4}$} & $\mathrm{ta} 5$ & $\mathrm{LR}$ & $\mathrm{BV}$ & $\mathrm{SV}$ \\
\hline $\mathrm{p}_{1}$ & $180-200,195(11)$ & $120-140,129(11)$ & $0.69-0.77,0.74(11)$ & $2.71-3.08,2.88(11)$ & $2.41-2.65,2.56(1)$ \\
$\mathrm{p}_{2}$ & $140-160,158$ & $100-120,118(11)$ & $0.58-0.68,0.61$ & $3.16-3.43,3.31$ & $3.00-3.39,3.26$ \\
$\mathrm{p}_{3}$ & $160-200,188(10)$ & $120-140,129(9)$ & $0.58-0.62,0.60(11)$ & $3.04-3.23,3.13(9)$ & $2.98-3.24,3.10(11)$ \\
\hline
\end{tabular}

Table 2. Lengths (in $\mu \mathrm{m}$ ) and proportions of legs of Tsudayusurika fudosecunda Sasa, 1985, female (n =4).

\begin{tabular}{cccccc}
\hline & $\mathrm{fe}$ & $\mathrm{ti}$ & $\mathrm{ta}_{1}$ & $\mathrm{ta}_{2}$ & $\mathrm{ta}_{3}$ \\
\hline $\mathrm{p}_{1}$ & $960-1020(3)$ & $1020-1200,1125$ & $700-840,800$ & $420-480,460$ & $280(3)$ \\
$\mathrm{p}_{2}$ & $960-1000(3)$ & $920-1060,1010$ & $620-700,650$ & $340-420,360$ & $220-260,230$ \\
$\mathrm{p}_{3}$ & $1040-1100(3)$ & $1140-1260,1215$ & $700-780(3)$ & $380-420(3)$ & $\mathrm{SV}$ \\
\hline & $\mathrm{ta} 4$ & $\mathrm{ta} 5$ & $\mathrm{LR}$ & $\mathrm{BV}$ & $280-300(3)$ \\
\hline $\mathrm{p}_{1}$ & $180(3)$ & $120(3)$ & $0.69-0.74,0.71$ & $2.75-2.83(2)$ & $2.56-2.57(3)$ \\
$\mathrm{p}_{2}$ & $140-180,155$ & $81(3)$ & $0.60-0.70,0.64$ & $3.14-3.20(2)$ & $3.09-3.29(3)$ \\
$\mathrm{p}_{3}$ & $160-180(2)$ & $120(2)$ & $0.61-0.63(3)$ & $3.02(1)$ & $2.92-3.05(2)$ \\
\hline
\end{tabular}

0.6, $0.4 \mathrm{~mm}$ wide; wing length / wing width 3.44-3.67, 3.53.

Coloration. As in male. Cercus brown.

Head. (Figures 1C-G). Temporal setae 5-6, uniserial. Flagellomere lengths (in $\mu \mathrm{m}, \mathrm{n}=2$ ): $58-62 ; 50 ; 56 ; 50-54 ; 54$; 42; 44-46; 40-42; 48; 80-98; with 2, 6, 6-7, 6, 6-7, 6, 6, 6, 5, 6-8 setae, respectively. Ultimate flagellomere without subapical seta. Palpomere lengths (in $\mu \mathrm{m}$ ): 22 (2); 34-52, 47; 98-110, 105 ; 78-81, 80; 90-120, 107; palpomeres with 0, 2-4, 12-15, 6-9, 6-7 setae, respectively; third palpomere with 4-8 sensilla clavata (Figures 1E, F). Clypeus with 1-4 setae. Cornua well developed.

Thorax. Lateral antepronotals 3 (3); dorsocentrals 6-8, uniserial; prealars 4-5, uniserial; acrostichals 3-9, biserial, supraalar 0 . Scutellum with 6 (3) setae, uniserial.

Wing. VR 1.07-1.17, 1.13. Costal extension as long as RM, ca. $90 \mu \mathrm{m}$ long. $\mathrm{R}$ with 16-18 setae, $\mathrm{R}_{1}$ with 11-13 setae and apical $1 / 2$ of $\mathrm{R}_{4+5}$ with11-15 setae. Brachiolum with 2-4 setae medially; with 8-12 basal, 3 median and 8 subapical sensilla campaniformia. Squama without setae.

Legs. Fore, mid and hind coxae with 2, 4-5, 4-6 marginal setae, respectively; fore, mid and hind trochanters with 7-8, 8-10, 5-7 marginal setae, respectively. Spur of fore tibia 48-54 $\mu \mathrm{m}$ long (3); mid tibia with anteroventral spur 24-26 $\mu \mathrm{m}$ long (2) and posteroventral spur 42-46, $45 \mu \mathrm{m}$ long; hind tibia with anterovental spur 24-28 $\mu \mathrm{m}$ long and posteroventral spur 62-72 $\mu \mathrm{m}$ long $(\mathrm{n}=2)$. Tibial comb with 7-11 spine-like setae. Lengths and proportions of legs as in Table 2.
Genitalia (Figures 2A-E). Sternum VIII with 28-33 setae. Tergum IX completely divided into two parts by a wide median longitudinal membrane. Tergite IX with 6-8 setae, laterostenite of T IX with 16-19 setae. Notum 180-224, $202 \mu \mathrm{m}$ long.

\section{Remarks.}

The type locality, Lake Fudo, is a crater lake situated in volcanic area in mid Kyushu. If the larvae are aquatic, they live in the highly acidic water in the crater lake where also Chironomus acerbiphilus Tokunaga, 1939 has been recorded.

\section{Distribution.}

Japan (Kyushu).

\section{Tsudayusurika kuroheius (Sasa) comb nov.}

(Figure 3A)

Kuroyonyusurika kuroheius Sasa, 1996: 23.

Bryophaenocladius kuroheius (Sasa); Sæther et al. (2000: 173); Yamamoto (2004: 10).

\section{Material examined.}

Holotype male (NMST, No. 284:24), Japan, Honshu, Toyama Pref., Mt. Tate, Kuroyon Lake, sweep net, 14. x. 1994, M. Sasa. 
Table 3. Lengths (in $\mu \mathrm{m}$ ) and proportions of legs of Tsudayusurika kuroheius, male ( $\mathrm{n}=1)$ (Holotype).

\begin{tabular}{ccccccccccc}
\hline & $\mathrm{fe}$ & $\mathrm{ti}$ & $\mathrm{ta}_{1}$ & $\mathrm{ta}_{2}$ & $\mathrm{ta}_{3}$ & $\mathrm{ta}_{4}$ & $\mathrm{ta}_{5}$ & $\mathrm{LR}$ & $\mathrm{BV}$ & $\mathrm{SV}$ \\
\hline $\mathrm{p}_{1}$ & - & - & - & - & - & - & - & - & - & - \\
$\mathrm{p}_{2}$ & 1024 & 1112 & 640 & 344 & 248 & 152 & 112 & 0.58 & 3.24 & 3.34 \\
$\mathrm{p}_{3}$ & 1168 & 1344 & - & - & - & - & - & - & - & - \\
\hline
\end{tabular}

\section{Diagnostic characters.}

Due to missing antennae of the holotypes of K. kuroheius and S. multiannulata and the missing hypopygium of the holotype of $S$. multiannulata, no certain diagnosis to separate the species from other taxa in Tsudayusurika can be given.

\section{Male $(\mathrm{n}=1)$.}

Total length $3.7 \mathrm{~mm}$. Wing $2.4 \mathrm{~mm}$ long, 0.6 wide; wing length / wing width 3.97 .

Coloration. As in T. fudosecunda.

Head (Sasa 1996: Figure 7a). Temporal setae 7. Antenna lost. Palpomere 1-4 lengths (in $\mu \mathrm{m}$; palpomere 5 lost): 32, 72, 160, 130; with 0. 4-5, 18, 11 setae, respectively; third palpomere with 4 sensilla clavata. Clypeus with 3 setae. Cornua weakly developed.

Thorax (Sasa 1996: Figure 7b, c). Lateral antepronotals 3; dorsocentrals 7, uniserial; acrostichals 6 , biserial; prealars 6 , uniserial; spuraalar 0. Scutellum with 6 setae, uniserial.

Wing (Sasa 1996: Figure 7d). Membrane with moderately strong punctuation. Anal lobe rounded. Costal extension as long as $\mathrm{RM}, 100 \mu \mathrm{m}$ long. VR 1.23 . $\mathrm{R}$ with 10 seta, $\mathrm{R}_{1}$ with 14 , apical $1 / 2$ of $R_{4+5}$ with 6 setae. Brachiolum with 4 median seta; with 9 basal, 3 median, and 8 subapical sensilla companiformia. Squama without setae.

Legs. Fore, middle and hind coxae with 2, 8, 6 marginal setae, respectively; fore, mid and hind trochanters with $8,8,6$ marginal setae, respectively. Mid tibia with anteroventral spur $42 \mu \mathrm{m}$ long, and with posteroventral spur broken; hind tibial spur broken. Distal portion of hind tibia do not form a distinct terminal comb as mentioned by Sasa's original description. Lengths and proportions of legs as in Table 3.

Hypopygium (Figure 3A; Sasa 1996: Figure 7j). Tergum IX with 15 setae on each side, sternum IX with 11 setae dorsolaterally. Gonocoxite $256 \mu \mathrm{m}$ long, with large, semicircular basal lobe, without microtrichia on dorsal surface, with microtrichia on basal 1/2 of ventral surface. Sternapodeme narrow, with weak rounded anterolateral projection; anterior margin slightly convex medially. Virga composed of 6 needle-like spines, $28 \mu \mathrm{m}$ long (Sasa, 1996). Gonostylus $122 \mu \mathrm{m}$ long. HR 2.10.

\section{Remarks.}

The presence or absence of a subapical seta on the ultimate flagellomere and a few setae (1-4 in number) on the clypeus are important taxonomic characters for identifying Tsudayusurika species. Unfortunately, we could not confirm the former character state because the antennae were lost in both holotypes of Kuroyonyusurika kuroheius and Spaniotoma multiannulata. The male shares the latter character state with $T$. fudosecunda and T. multiannulata. The paramere of the species are smaller than those of T. fudosecunda and T. suginoi, but as the male genitalia of the holotype is lost, we cannot compare the paramere with that of T. multiannulata. The species might thus be a synonym of either T. fudosecunda or T. multiannulata. If so, it is most probably a synonym of $T$. multiannulata due to the small paramere.

Distribution.

Japan (Honshu).

\section{Tsudayusurika multiannulata (Tokunaga)}

(Figures 3-5.)

Spaniotoma (Orthocladius) multiannulata Tokunaga, 1940: 287.

Tsudayusurika multiannulata (Tokunaga); Sasa \& Kikuchi (1995: 74, 185).

\section{Material examined.}

Holotype male (Tokunaga Collection No. 2: 16, Kyushu University), Formosa, Arisan, 27.xii.1936, M. Tokunaga (head and genitalia lost). Allotype female, as holotype. 1 female, Japan, Honshu, Kyoto Prefecture, Yakuno, 13.viii.2003, light trap, M. Sasakawa.

\section{Diagnostic characters.}

The species can be easily separated from both T. fudosecunda and T. suginoi $\mathrm{sp}$. n. on the comparative narrow median longitudinal membranous area on T IX in the female. Furthermore, in the female, the species is also distinct from T. suginoi $\mathrm{sp} . \mathrm{n}$. by having 4 setae on the clypeus and from T. fudosecunda as the ultimate antennal flagellomere has a subapical seta. Diagnostic characters in the male are not certain due to the missing antennae of the holotype. However, based on female characteristics, the ultimate antennal flagellomere should bear a subapical seta and this would separate T. multiannulata from $T$. fudosecunda, the other species with 8-10 setae on clypeus.

\section{Holotype male.}

Tokunaga (1940) give the total length as about $3.8 \mathrm{~mm}$, the antennal ratio as about 2.44 , and the coloration as follows: thorax black, shiny; leg entirely dark brown, abdomen of male 
Table 4. Lengths (in $\mu \mathrm{m})$ and proportions of legs of Tsudayusurika multiannulata, male $(\mathrm{n}=1)$ (Holotype).

\begin{tabular}{ccccccccccc}
\hline & $\mathrm{fe}$ & $\mathrm{ti}$ & $\mathrm{ta}_{1}$ & $\mathrm{ta}_{2}$ & $\mathrm{ta}_{3}$ & $\mathrm{ta}_{4}$ & $\mathrm{ta}_{5}$ & $\mathrm{LR}$ & $\mathrm{BV}$ & $\mathrm{SV}$ \\
\hline $\mathrm{p}_{1}$ & 1320 & 1580 & 1240 & 660 & 380 & 220 & 140 & 0.78 & 2.96 & 2.34 \\
$\mathrm{p}_{2}$ & 1320 & 1440 & 840 & 460 & 300 & 190 & 140 & 0.58 & 3.30 & 3.29 \\
$\mathrm{p}_{3}$ & 1400 & 1860 & - & - & - & - & - & - & - & - \\
\hline
\end{tabular}

Table 5. Lengths (in $\mu \mathrm{m}$ ) and proportions of legs of Tsudayusurika multiannulata, female ( $\mathrm{n}=1$ ) (Allotype).

\begin{tabular}{cccccccccccc}
\hline & $\mathrm{fe}$ & $\mathrm{ti}$ & $\mathrm{ta}_{1}$ & $\mathrm{ta}_{2}$ & $\mathrm{ta}_{3}$ & $\mathrm{ta}_{4}$ & $\mathrm{ta}_{5}$ & $\mathrm{LR}$ & $\mathrm{BV}$ & $\mathrm{SV}$ \\
\hline $\mathrm{p}_{1}$ & 1280 & 1540 & 1300 & 720 & 420 & 200 & 140 & 0.84 & 2.78 & 2.17 \\
$\mathrm{p}_{2}$ & 1280 & 1340 & 860 & 440 & 280 & 160 & 120 & 0.64 & 3.48 & 3.05 \\
$\mathrm{p}_{3}$ & 1380 & 1740 & 1080 & 540 & 380 & 200 & 140 & 0.62 & 3.33 & 2.89 \\
\hline
\end{tabular}

Table 6. Lengths (in $\mu \mathrm{m}$ ) and proportions of legs of Tsudayusurika multiannulata, female ( $\mathrm{n}=1$ ) (Yakuno).

\begin{tabular}{ccccccccccc}
\hline & $\mathrm{fe}$ & $\mathrm{ti}$ & $\mathrm{ta}_{1}$ & $\mathrm{ta}_{2}$ & $\mathrm{ta}_{3}$ & $\mathrm{ta}_{4}$ & $\mathrm{ta}_{5}$ & $\mathrm{LR}$ & $\mathrm{BV}$ & $\mathrm{SV}$ \\
\hline $\mathrm{p}_{1}$ & 940 & 1140 & 800 & 420 & 280 & 180 & 120 & 0.70 & 2.88 & 2.60 \\
$\mathrm{p}_{2}$ & 1020 & 1020 & 560 & 300 & 200 & 140 & 100 & 0.55 & 3.51 & 3.62 \\
$\mathrm{p}_{3}$ & 1100 & 1280 & 720 & 380 & 300 & 160 & 120 & 0.56 & 3.23 & 3.31 \\
\hline
\end{tabular}

dark brown, each tergum with a narrow dark caudal band.

Thoracic and cephalic setation not observable.

Anal lobe of wing distinct, rounded. Squama with weak 1 seta.

Lengths and proportions of legs are given from the holotype

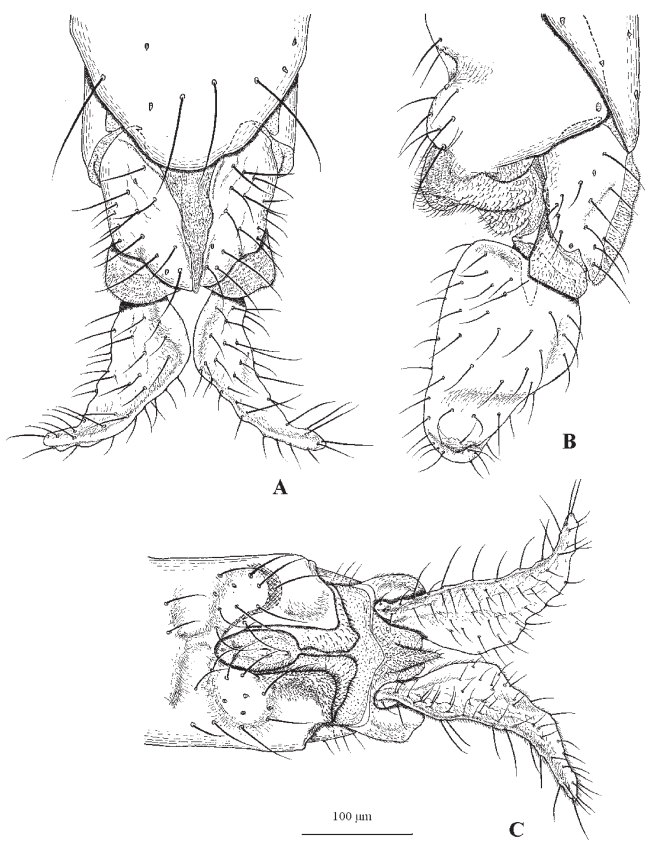

Figure 5. Tsudayusurika multiannulata (Tokunaga, 1940), female genitalia (Yakuno, Kyoto Pref., Honshu, Japan). A. dorsal view. B. lateral view. $\mathrm{C}$. ventral view. as in Table 4.

Tokunaga (1940: Figure 57) gives the illustration of the gonostylus. However it is difficult to separate this species from other congeneric species based on the shape of the gonostylus.

\section{Allotype female.}

Total length $2.7 \mathrm{~mm}$.

Head. Temporal setae 5. Second to ultimate flagellomere lengths (in $\mu \mathrm{m}$ ): $50,52,44,52,50,50,48,54,102 ; 4^{\text {th }}$ to ultimate flagellomere with $6,6,6,6,6,6$, at least 7 setae, respectively. Ultimate flagellomere with subapical seta. Maxillary palpus broken. Clypeus with 4 setae. Cornua short but distinct.

Thorax. Lateral antepronotals 2; dorsocentrals 7, uniserial; prealars 5, uniserial; acrostichals not countable; supraalar 0 . Wing. Squama with 4 setae. Setae on veins not countable.

Legs. Fore, mid coxae with 2, 8 marginal setae, respectively; mid trochanter with 9 marginal setae. Spur of fore tibia $66 \mu \mathrm{m}$ long; mid tibia with posteroventral spur $54 \mu \mathrm{m}$ long. Tibial comb with 12 spine-like setae. Lengths and proportions of legs as in Table 5.

Genitalia (Figures 3B-D). Tergum IX completely divided into two parts by comparatively narrow median longitudinal membrane, and each tergite with 3 or 4 setae; laterosternite with 15 setae. Notum ca. $200 \mu \mathrm{m}$ long.

\section{Additional female specimen $(\mathrm{n}=1)$}

Total length $3.7 \mathrm{~mm}$. Wing $2.6 \mathrm{~mm}$ long, $0.8 \mathrm{~mm}$ wide, wing length / wing width 3.12.

Head (Figures 4A-E). Temporal setae 7. Flagellomere lengths 
(in $\mu$ m): $78,60,56,56,52,52,52,48,56,106$; with $6,6,6,6$, $6,6,6,6,6,10$ setae, respectively. Ultimate flagellomere with subapical seta. Palpomere lengths (in $\mu \mathrm{m}$ ): 30, 50, 100, 96, 138; palpomeres with $0,1,9,8,4$ setae, respectively; third palpomere with 3 sensilla clavata. Clypeus with 4 setae. Cornua short but distinct.

Thorax (Figure 4F). Lateral anteronotals 3; dorsocentrals 11 or 12 , prealars 6 , both uniserial; acrostichals 3 ; supraalar 0 . Scultellum with 8 setae, uniserial.

Wing. VR 1.10. Costal extension as long as RM, $108 \mu \mathrm{m}$ long. $R$ with 17 setae, $R_{1}$ with 14 setae and apical $3 / 4$ of $R_{4+5}$ with 26 setae. Brachiolum with 3 or 4 median setae; with 12 basal, 3 or 4 median, 10 subapical sensilla companiformia. Squama with 8 or 10 setae.

Legs. Fore, mid and hind coxae with 2, 6, 7 marginal setae, respectively; fore, mid and hind trochanters each with 9 marginal setae. Spur of fore tibia $64 \mu \mathrm{m}$ long; mid tibia with anteroventral spur $18 \mu \mathrm{m}$ long and posteroventral spur $50 \mu \mathrm{m}$ long; hind tibia with anteroventral spur broken and posteroventral spur $70 \mu \mathrm{m}$ long. Tibial comb with 10 spine-like setae. Lengths and proportions of legs as in Table 6.

Genitalia (Figures 5A-C). Sternum VIII with 31 setae. Tergum IX completely divided into two parts by a narrow median longitudinal membrane, and each tergite with 4 setae; laterosternite with 10 or 12 setae. Notum ca. $260 \mu \mathrm{m}$ long. Postgenital plate slender and long.

\section{Distribution.}

Taiwan (Arisan), Japan (Honshu).

\section{Tsudayusurika suginoi sp. n.}

(Figures 6-8)

\section{Type material:}

Holotype: male (OPU-IN-DI2001X0001), slide mounted in Euparal: Japan, Ryukyus, Okinawa Prefecture, Okinawa Island, Kunigami-son, Aha, malaise trap. 17-23.i.2009, K. Sugino. Paratypes: 9 males, 4 females, as previous except 7-17.i.2009; 3 females, as holotype; 3 females, as previous except 23.i.4.ii.2009.

\section{Diagnostic characters.}

The species is distinct from the other species by the ultimate antennal flagellomere bearing a subapical seta, clypeus with several to 10 setae and the triangular basal lobe of gonocoxite in hypopygium.

\section{Etymology.}

Named in honour of Mr. K. Sugino of Okinawa Prefecture, the collector of the material examined.

Male ( $\mathrm{n}=10$, unless otherwise stated)

Total length 3.1-3.5, $3.3 \mathrm{~mm}$. Wing 2.1-2.2, $2.1 \mathrm{~mm}$ long, 0.5-

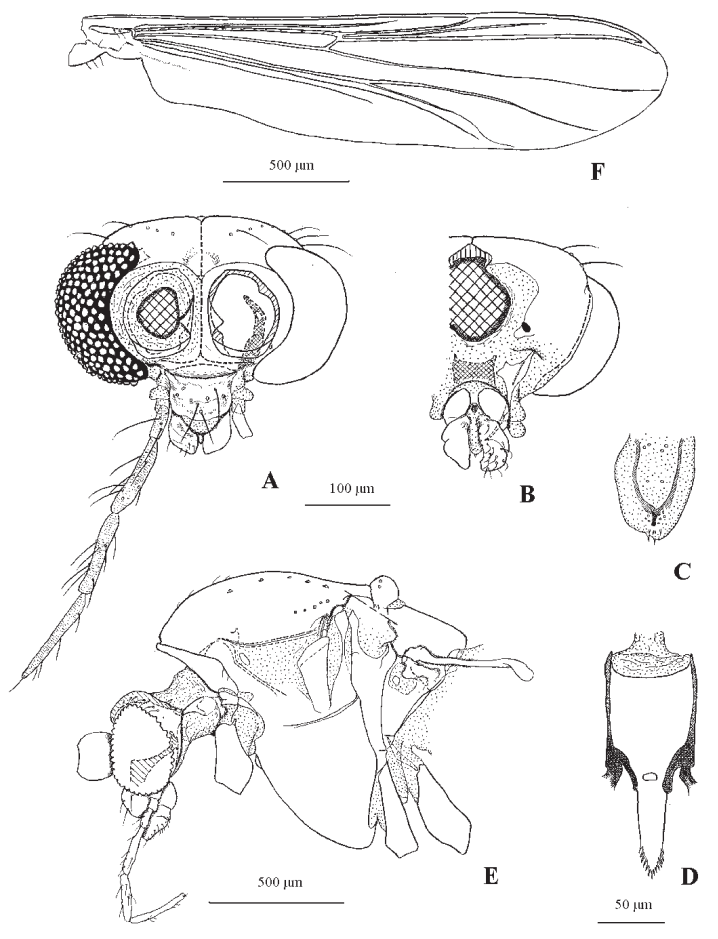

Figure 6. Tsudayusurika suginoi sp, nov., male. A. head, frontal view. B. head, caudal view. C. epipharynx, dorsal view. D. cibarial pump, dorsal view. E. head and thorax, lateral view. F. wing.

0.6, $0.5 \mathrm{~mm}$ wide; wing length / wing width 3.71-4.04, 3.87.

Coloration. As in Tsudayusurika fudosecunda.

Head (Figures 6A-D). Temporal setae 6-11. AR 1.65-1.90, 1.75. Ultimate flagellomere with subapical seta. Palpomere lengths (in $\mu \mathrm{m}$ ): 26-36, 30; 48-66, 56; 126-142, 133; 120-140, 131; 146176,165 ; with 0, 2-6, 11-15, 9-11, 6-9 setae, respectively. Cornua weakly developed. Clypeus with 7-9 setae.

Thorax (Figure 6E). Lateral antepronotals 1-3; dorsocentals 5-9, uniserial; acrostichals 2-7, biserial; prealars 4-6, uniserial; supraalar 0. Scutellum with 5-9 setae, uniserial.

Wing (Figure 6F). VR 1.08-1.16, 1.13. Costal extension as long as $\mathrm{RM}$, ca. $80 \mu \mathrm{m}$ long. $\mathrm{R}$ with $12-14$ setae, $\mathrm{R}_{1}$ with $4-8$ setae and apical $1 / 6-1 / 3$ of $R_{4+5}$ with $2-7$ setae. Brachiolum with 3-4 (mostly 3) median setae, with 10-11 basal, 3 median, 9-10 subapical sensilla campaniformia. Squama with 2-4 setae.

Legs. Fore, mid and hind coxae with 1-2 (mostly 2), 4-7, 4-8 marginal setae, respectively; fore, mid and hind trochanters with 8-11, 8-11, 7-12 marginal setae, respectively. Spur of fore tibia 46-64, $56 \mu \mathrm{m}$ long; mid tibia with anteroventral spur $18-26,23 \mu \mathrm{m}$ long and posteroventral spur $38-42,41 \mu \mathrm{m}$ long; hind tibia with anteroventral spur 24-32, $27 \mu \mathrm{m}$ long and posteroventral spur 46-62, $56 \mu \mathrm{m}$ long. Tibial comb of hind leg with 11-15 spine-like setae. Lengths and proportions of legs as in Table 7.

Hypopygium (Figures 7A-C). Tergum IX with 5-7 (6) setae on each side, S IX with 10-13 (6) setae dorsolaterally. Gonocoxite 

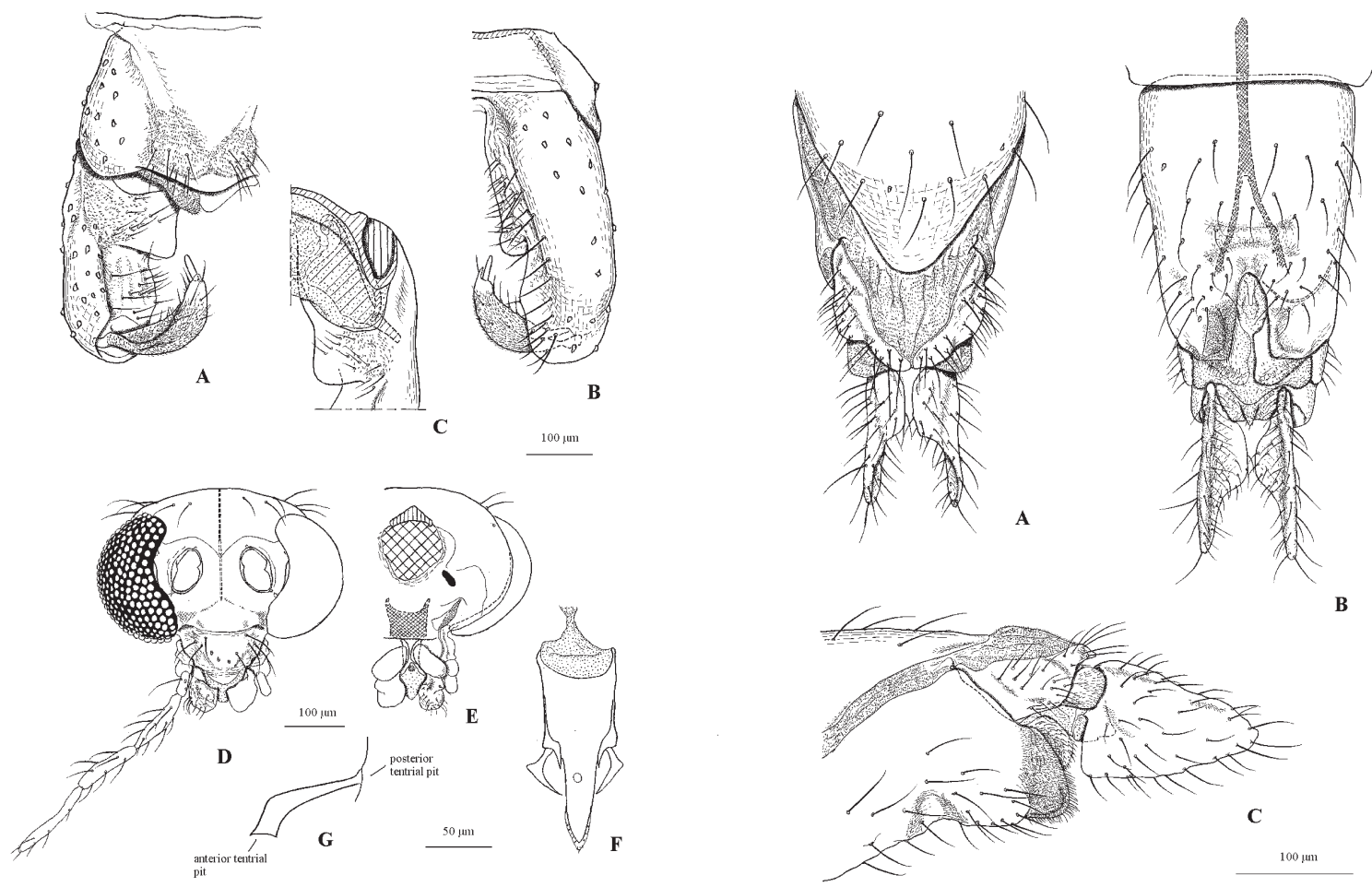

Figure 7. Tsudayusurika suginoi sp. nov, male hypopygium (A-C) and female head (D-G). A. dorsal view. B. ventral view. C. basal portion of gonocoxite, excluding T IX. D. head, frontal view. E.

Figure 8. Tsudayusurika suginoi sp. nov., female genitalia. A. dorsal view. B. ventral view. C. lateral view. head, caudal view. F. cibarial pump, dorsal view. G. tentorium, lateral view.

Table 7. Lengths (in $\mu \mathrm{m}$ ) and proportions of legs of Tsudayusurika suginoi n. sp., male ( $\mathrm{n}=9$ ).

\begin{tabular}{|c|c|c|c|c|c|}
\hline & fe & $\mathrm{ti}$ & $\operatorname{ta}_{1}$ & $\mathrm{ta}_{2}$ & $\mathrm{ta}_{3}$ \\
\hline $\mathrm{p}_{1}$ & $940-1100,1017$ & $1020-1200,1135$ & $860-900,880$ & $440-480,460$ & $260-300,287$ \\
\hline $\mathrm{p}_{2}$ & $920-1040,989$ & $980-1180,1031$ & $600-660,625(8)$ & $300-340,313(8)$ & $200-240,220(8)$ \\
\hline \multirow[t]{2}{*}{$\mathrm{p}_{3}$} & $1000-1160,1080$ & $1200-1280,1231$ & $720-780,753$ & $360-400,380$ & $260-280,275$ \\
\hline & $\mathrm{ta}_{4}$ & $\operatorname{ta}_{5}$ & LR & BV & SV \\
\hline $\mathrm{p}_{1}$ & $140-180,167$ & $100-120,117$ & $0.72-0.88,0.77$ & $2.81-3.09,2.94$ & $2.20-2.56,2.45$ \\
\hline $\mathrm{p}_{2}$ & $120-140,133(8)$ & $100-120,105(8)$ & $0.53-0.64,0.60$ & $3.26-3.89,3.44$ & $3.09-3.58,3.24$ \\
\hline $\mathrm{p}_{3}$ & $140-160,158$ & $100-120,113$ & $0.59-0.63,0.62$ & $3.13-3.52,3.31$ & $2.97-3.21,3.07$ \\
\hline
\end{tabular}

Table 8. Lengths (in $\mu \mathrm{m})$ and proportions of legs of Tsudayusurika suginoi $n$. sp. female $(\mathrm{n}=10)$.

\begin{tabular}{cccccc}
\hline & $\mathrm{fe}$ & $\mathrm{ti}$ & $\operatorname{ta}_{1}$ & $\operatorname{ta}_{2}$ & $\mathrm{ta}_{3}$ \\
\hline $\mathrm{p}_{1}$ & $5840-980,912$ & $980-1200,1086$ & $760-980,874$ & $420-560,484(9)$ & $200-300,267(9)$ \\
$\mathrm{p}_{2}$ & $780-960,902$ & $840-1020,978$ & $500-660,608$ & $260-340,312$ & $160-240,204$ \\
$\mathrm{p}_{3}$ & $820-1040,988$ & $1060-1240,1180$ & $660-760,711(7)$ & $360-400,366(7)$ & $240-280,263(7)$ \\
\hline & $\operatorname{ta}_{4}$ & $\operatorname{ta}_{5}$ & $\mathrm{LR}$ & $\mathrm{BV}$ & $\mathrm{SV}$ \\
\hline $\mathrm{p}_{1}$ & $120-160,148(9)$ & $100-120,104(9)$ & $0.78-0.83,0.80$ & $2.73-2.98,2.87(9)$ & $2.19-2.40,2.29$ \\
$\mathrm{p}_{2}$ & $120-140,126$ & $80-100,96$ & $0.60-0.65,0.62$ & $3.21-3.50,3.37$ & $2.91-3.24,3.09$ \\
$\mathrm{p}_{3}$ & $120-160,137(7)$ & $100-120,103(7)$ & $0.58-0.62(7)$ & $3.22-3.42,3.31(7)$ & $2.85-3.14,3.04(7)$ \\
\hline
\end{tabular}


200-220, $213 \mu \mathrm{m}$ long, with large, nearly triangular basal lobe. Sternapodeme narrow, convex medially, with moderately produced anterolateral projection. Virga of several needle-like spines, about $10 \mu \mathrm{m}$ long. Gonostylus 92-104, $99 \mu \mathrm{m}$ long; megaseta 16-22, $20 \mu \mathrm{m}$ long. HR 2.04-2.27, 2.16.

Female ( $\mathrm{n}=10$, unless otherwise stated)

Total length 2.8-3.5, 3.1 mm. Wing 2.0-2.2, $2.1 \mathrm{~mm}$ long; 0.60.7, $0.6 \mathrm{~mm}$ wide; wing length / wing width 3.31-3.49, 3.29 (7). Coloration. As in male. Cercus pale brown.

Head (Figures 7D-G). Temporal setae 5-7. Flagellomere lengths (in $\mu \mathrm{m}$ ): $60-66,63$; 50-56, 51; 46-56, 52; 46-56, 49; 42-50, 48; 40-48, 44; 38-44, 43 (9); 40-42, 41 (8); 40-48, 44 (8); 66-86, 77 (8); with 3-4, 5-6, 5-6, 5-6, 6-7, 5-6, 5-6 (9), 5-6 (8), 5-6 (8), 6-7 (8) setae, respectively. Ultimate flagellomere with subapical seta. Palpomere lengths (in $\mu \mathrm{m} ; \mathrm{n}=8$ ): 20-34, 27; 40-50, 45; 100-116, 105; 94-118, 107; 138-164, 150; palpomeres with 0, 2-5, 8-16, 9-12, 5-9 setae, respectively. Clypeus with 8-10 setae.

Thorax. Lateral antepronotals 1-3; dorsocentrals 6-9, uniserial; prealaras 4-6, uniserial; acrostichals 2-6, biserial; supraalar 0. Scutellum with 6-8 (9) setae, uniserial.

Wing. VR 1.00-1.17, 1.11. Costal extension as long as RM, ca. $80 \mu \mathrm{m}$ long. $\mathrm{R}$ with $12-17$ setae $(7), \mathrm{R}_{1}$ with 7-12 (7) setae and apical $1 / 3-1 / 2$ of $\mathrm{R}_{4+5}$ with $12-17$ (7) setae. Brachiolum (8) with 2-3 median setae; with 10 basal, 3 median, 9-11 subapical sensilla campaniformia. Squama with 1-5 (7) setae.

Legs. Fore, mid and hind coxae with 1-3, 4-6 (9), 2-7 (9) marginal setae, respectively; fore, mid and hind trochanters with 6-10, 8-10 (9), 8-10 (9) marginal setae, respectively. Spur of fore tibia $30-48,40 \mu \mathrm{m}$ long; mid tibia with anteroventral spur 12-28, $20 \mu \mathrm{m}$ long and posteroventral spur 32-42, $38 \mu \mathrm{m}$ long; hind tibia with anteroventral spur 16-24, $20 \mu \mathrm{m}$ long and posteroventral spur 46-54, $50 \mu \mathrm{m}$ long. Tibial comb with 8-12 spine-like setae. Lengths and proportions of legs as in Table 8. Genitalia (Figures 8A-C). Sternum VIII with 46-53 setae (6). Tergum IX completely divided into two parts by a wide median longitudinal membrane, and tergite with 6-9 setae; laterostenite with 13-18 setae. Notum 216-228, $222 \mu \mathrm{m}$ long.

\section{Distribution.}

Japan (Okinawa Island).

\section{"Tsudayusurika cladochaita" Wang}

Wang 1995, Figure 1. (A-F).

\section{Tsudayusurika cladochaita Wang, 1995: 49.}

This species differs from all other known species of Tsudayusurika in having an extremely short maxillary palp, branched sensilla chaetae (long sensilla basiconica) on flagellomere, conspicuously extended costa, no anal point, no virga and no basal lobe of gonocoxite. This species certainly does not belong to Tsudayusurika, but quite possibly to
Bryophaenocladius, or perhaps to a hitherto unnamed genus. Further study of the species and particularly of the female is required for a certain assignment.

\section{“Tsudayusurika yufunivea” (Sasa et Suzuki) Sasa and Suzuki 1991, Figure 5.3. (a-c).}

Epoicocladious yufuniveus Sasa et Suzuki, 1991: 98. Tsudayusurika yufunivea (Sasa et Suzli); Yamamoto (2004: 109).

Unfortunately the holotype of this species is missing. This species was transferred to the genus Tsudayusurika by Yamamoto (2004) based on the original description. The setose basal lobe with a few comparatively long setae on its posterior margin and the gonostylus with inner convex margin at about mid-length are different from any Tsudayusurika. This species certainly does not belong to Tsudayusurika, but possibly to Bryophaenocladius.

\section{ACKNOWLEDGMENTS}

We are indebted to Dr. O. Tadauchi and Dr. S. Kamitani, Entomological Laboratory, Faculty of Agriculture, Kyushu University, Fukuoka and Dr. A. Shinohara, the National Museum of Nature and Science, Tokyo, for the loan of the type material. We are especially thankful to Mr. K. Sugino of Kunigami Tourism Association, Okinawa and Dr. M. Sasakawa of Osaka Prefecture for offering invaluable specimens. We thank to Dr. P. S. Cranston, Australian National University, Canberra, Australia, for correcting the language of the manuscript and valuable suggestions. Cordial thanks are also due to two anonymous reviewers for their valuable advices.

\section{REFERENCES}

Cranston PS. 1987. A non-biting midge (Diptera: Chironomidae) of horticultural significance. Bulletin of entomological Research, 77: 661-667.

Cranston PS, Dillon ME, Pinder CV, Reiss F. 1989. The adult males of Chironominae (Diptera: Chironomidae) of the Holarctic region - Keys and diagnoses. In: Wiederholm. T. (Ed.), Chironomidae of the Holarctic region. Keys and diagnoses. Part 3. Adult males. Entomologica scandinavica, Supplement, 34: 353-532.

Sæther OA. 1977. Female genitalia in Chironomidae and other Nematocera: morphology, phylogenies, keys. Bulletin of the Fisheries Research Board of Canada, 197: 1-211.

Sæther OA. 1980. Glossary of chironomid morphology terminology (Diptera: Chiromomidae). Entomologica scandinavica, Supplement, 14: 1-52.

Sæther OA, Ashe P, Murray DE. 2000. Family Chironomidae. In: Papp L and Darvas B (eds). Contributions to a Manual 
of Palaearctic Diptera (with special reference to the flies of economic importance). Vol. 4. Appendix A. 6. Science Herald, Budapest, pp. 113-334.

Sasa M. 1985b. Studies on chironomid midges of some lakes in Japan. Part II. Studies on the chironomids collected from lakes in southern Kyushu (Diptera, Chironomidae). Research Report from the National Institute for Environmental Study, 83: 25-99.

Sasa M. 1996. Studies on the Chironomidae of Japan, 1996. A. Studies on the chironomids collected at the side of Kuroyon Lake and on the highlands of Mount Tate area, Toyama. Toyama Prefectural Environmental Science Research Center, 1996 (December): 16-47.

Sasa M. Kikuchi M. 1995. Chironomidae (Diptera) of Japan. University of Tokyo Press, Tokyo: 333pp.

Sasa M, Suzuki H. 1991. The chironomids of the Joganji River and other places. Part 5. Studies on the chironomids of the Aso National Park area, Kyusyu. Toyama Prefectural Environmental Science Research Center, 1991: 93-100.

Tokunaga M. 1940. Chironomidae from Japan (Diptera), XII New or little-known Ceratopogonidae and Chironomidae. Philippine Journal of Science, 72: 255-311.

Wang X. 1995. Two new and unusual species from oriental China (Diptera: Chironomidae). Acta Scientiarum Naturalium Universitatis Nankaiensis, 28: 48-53.

Yamamoto M. 2004. A catalog of Japanese Orthocladiinae (Diptera: Chironomidae). Makunagi/Acta Dipterologica, 21: 1-121. 